\title{
Mixed Matrix Membranes for pervaporation study from Crosslinked Poly (vinyl alcohol) (PVA) Composited with Zeolite $\mathrm{NaY}$
}

\author{
Dr. A. A. Kittur \\ Professor, Department of Chemistry, SDM College of Engineering \& Technology, Dharwad, Karnataka
}

\begin{abstract}
Poly(vinyl alcohol) membranes were developed by physico-chemical cross linking method. The membranes were crosslinked with Glutaraldehyde and filled with $\mathrm{NaY}$ zeolite to bring both physical and chemical change among the membrane. The physico-chemical properties of the resulting membranes were studied by Fourier transform Infrared Spectroscopy (FTIR), wide-angle X-ray diffraction (WAXD), differential scanning calorimetry (DSC), thermogravimetric analysis (TGA) and scanning electron microscopy (SEM) techniques. The mechanical properties of the membranes were studied using universal tensile machine (UTM). The prepared membranes were subjected for pervaporation (PV) study of separation of water-isopropanol mixtures in the temperature range of $30-50{ }^{\circ} \mathrm{C}$. The experimental results demonstrated that the developed membranes containing 15 mass $\%$ of crosslinking agent showed the highest separation selectivity of 3,442 with a flux of $3.71 \times 10^{-2} \mathrm{~kg} / \mathrm{m}^{2} \mathrm{~h}$ at $30^{\circ} \mathrm{C}$ for 10 mass $\%$ of water in the feed.
\end{abstract}

Keywords:poly(vinyl alcohol), Glutaraldehyde, NaY-zeolite, Pervaporation, Selectivity, Activation energy.

\section{INTRODUCTION}

Isopropanol (IPA) is widely used in many industries particularly in petroleum and pharmaceutical industries as one of the important solvents and cleansers. Its large scale utilization in IT sector is as a cleaning agent more specifically in modern semiconductor and liquid crystal display industries. Hence, recycling of waste IPA is necessary for both environmental and economical point of view. But, IPA and water form an azeotropic mixture at 87.4 mass\% of IPA concentration, the separation of these mixtures by conventional methods such as solvent extraction, rotavapor and distillation is very difficult and the process becomes uneconomical [1-3].

Pervaporation (PV) is a membrane-based separation technology that has been actively explored for the separation of liquid mixtures especially azeotropic mixtures and close boiling liquids due to their easy operation, cost effective, energy saving and eco-friendly nature [4-6]. In PV, the separation process occurs by the solution-diffusion principle and the process takes place in three steps: sorption of liquid at the upstream side of the membrane surface, diffusion of liquids through the membrane and desorption of the sorbed molecules in vapor form at downstream side of the membrane by applying vacuum $[7,8]$. A good result of pervaporation process is mainly dependent synthesis of suitable membranes, selection of suitable membrane material and its modification.

Continuous efforts were carried out by many researchers to develop new polymeric membranes. Literature survey reveals that several reports have been published using different types of hydrophilic polymers including poly(vinyl alcohol) (PVA), sodium alginate and chitosan as a membrane material in PV separation of aqueous-organic mixtures [9-13]. Among all, PVA is still attracting more researchers and has been extensively used as a membrane material because of the excellent film forming property and hydrophilic character.

PVA is one of the most important water-soluble vinyl polymers [14]. The hydroxyl groups in PVA can form strong hydrogen bonds between intra and intermolecular hydroxyl groups. This causes PVA to show high affinity towards water. The drawback with PVA is high crystallinity, high swelling which decreases its performance in PV experiments. To enhance this quality, and to get good mechanical property and achieve better selectivity towards water PVA needs modification. Several modification methods are in practice among these, crosslinking method has been extensively used to modify the membranes [15-19].

In the present study, we have made an attempt to develop modified-poly(vinyl alcohol) membranes by crosslinking with Glutaraldehyde to bring chemical change. Here, some of the hydroxyl groups of PVA react with the crosslinker. Apart from this chemical change, physical modification is also done by filling hydrophilic zeolite i.e., NaY. Zeolites are porous crystalline framework materials consisting of the $\mathrm{SiO}_{4}$ and $\mathrm{AlO}_{4}$ tetrahedrons [20]. These tetrahedrons are connected by sharing the atom of oxygen. Aluminum in the center of $\mathrm{AlO}_{4}$ tetrahedron is negatively charged and can be compensated by exchangeable metal cation $\left(\mathrm{Na}^{+}, \mathrm{K}^{+}\right)$[20]. $\mathrm{NaY}$ is a part of the faujasite (FAU) group of the zeolites [21]. Moreover, it is characterized by a large pore size equal to $7.4 \AA$ and a size cage equal to $11.8 \AA$ [22]. This zeolite possesses a durable hydrophilic nature and high resistance to water. Due to the excellent properties, $\mathrm{NaY}$ has been chosen as a filler material 


\section{International Advanced Research Journal in Science, Engineering and Technology}

Vol. 8, Issue 6, June 2021

DOI: $10.17148 /$ IARJSET.2021.8696

for the dehydration of alcohol [23]. FAU type membranes were also applied for ethanol dehydration and separation of organic solvent mixtures (alcohol/benzene, cyclohexane, methyl tert-butyl ether, or ethyl tert-butyl ether) by pervaporation [24]. Zeolite NaY membranes were prepared by the continuous intergrowth of zeolite crystals. The physico-chemical changes occur in the resulting crosslinked membranes were investigated using FTIR, WAXD, DSC and SEM. The mechanical properties of the membranes were studied by UTM. The membranes were employed for the separation of water-IPA mixtures at different temperatures. The diffusion coefficients were calculated from the modified Fick's equation and the results were discussed in terms of PV separation efficiency of the membranes.

\section{EXPERIMENTAL METHODS}

\subsection{Materials}

Poly(vinyl alcohol) $\left(\bar{M}_{w} \sim 125,000,87.5 \%\right.$ hydrolyzed), Glutaraldehyde, and isopropanol were procured from s. d. Fine Chemicals Ltd., Mumbai, India. NaY zeolite synthesized hydrothermally. All the chemicals were of reagent grade and used without further purification. Double distilled water was used in this study.

2.2. Hydrothermal synthesis of NaY zeolite

To prepare structure directing agent Sodium aluminate solution $(20 \mathrm{wt} \%)$ was mixed with sodium silicate solution (30 $\mathrm{wt} \%$ ) for $10 \mathrm{~min}$ in a reaction vessel. Then the solution was aged continuously and obtained the desired solution with a typical composition of $9.5 \mathrm{Na}_{2} \mathrm{O} \cdot \mathrm{Al}_{2} \mathrm{O}_{3} \cdot 10 \mathrm{SiO}_{2} .720 \mathrm{H}_{2} \mathrm{O}$.

Initial solution was prepared by mixing Sodium aluminate solution (30 wt \%) with sodium hydroxide solution (7 wt $\%$ ) and sodium silicate solution (30 wt. \%). The initial solution was obtained with a typical composition $2.5 \mathrm{Na}_{2} \mathrm{O} \cdot \mathrm{Al}_{2} \mathrm{O}_{3} \cdot 4 \mathrm{SiO}_{2} \cdot 240 \mathrm{H}_{2} \mathrm{O}$. The resulting gel-like mixture was aged for $24 \mathrm{~h}$ and crystallized at $100{ }^{\circ} \mathrm{C}$ for $12 \mathrm{~h}$, and then calcined at $450{ }^{\circ} \mathrm{C}$ for $3 \mathrm{~h}$ in air to get $\mathrm{NaY}$ zeolite $[25,26]$.

2.2. Membrane preparation

Poly(vinyl alcohol) $(4 \mathrm{~g})$ was dissolved in $100 \mathrm{ml}$ of deaerated-distilled water at $60{ }^{\circ} \mathrm{C}$. The hot solution was filtered and to the filtrate, a known amount of $\mathrm{NaY}$ zeolite $(2.5 \mathrm{wt} . \%)$ was added. The solution was further stirred overnight at $60{ }^{\circ} \mathrm{C}$ to get filler polymer stable dispersion. It was then mixed with $2 \mathrm{wt} \% \%$ of aqueous solution of glutaraldehyde crosslinker and the resulting homogeneous solution was cast onto a glass plate with the aid of a casting knife. The membranes were allowed to dry at room temperature for 2-3 days and the completely dried membranes were subsequently peeled-off from the glass plate, and then heated in a thermosetting oven at $120^{\circ} \mathrm{C}$ for $1 \mathrm{~h}$ to induce crosslinking reaction. For the purpose of comparison, we have also prepared pure PVA membrane which is designated as $\mathrm{M}$. The thickness of the membranes was measured at different points using a Peacock dial thickness gauge (Model G, Ozaki Mfg. Co. Ltd., Japan) with an accuracy of $\pm 2 \mu \mathrm{m}$ and the average thickness was considered for the calculation. The thickness of the membranes was found to be $40 \pm 2 \mu \mathrm{m}$. The reaction scheme for the poly(vinyl alcohol) membranes crosslinked with is illustrated in Fig.

1.

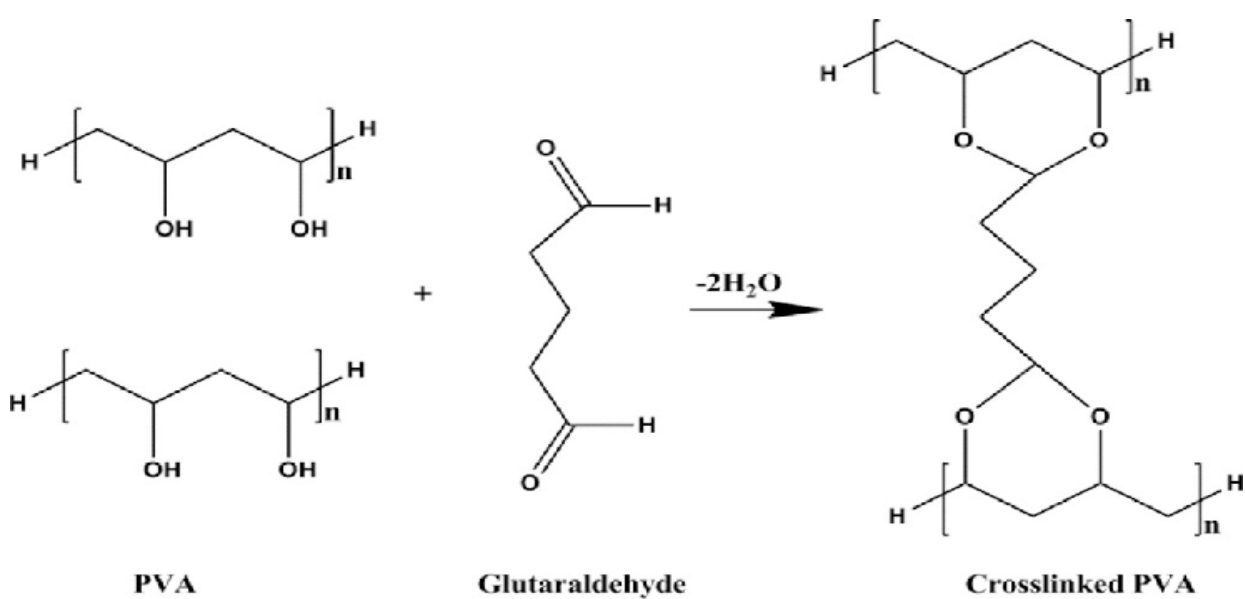

Fig. 1. Scheme for the synthesis of GA crosslinked poly(vinyl alcohol) membrane.

2.3. Membrane characterization

2.3.1. Fourier transform infrared spectroscopy (FTIR)

Nicolet, impact-410, USA FTIR spectrometer is used to confirm the chemical reaction between PVA and Glutaraldehyde and Physical changes occurred by NaY zeolite in the membranes. The virgin PVA membrane and modified membrane samples were used and the spectra were recorded in the range of 500-4000 $\mathrm{cm}^{-1}$.

2.3.2. Wide-angle X-ray diffraction (WAXD) 


\section{International Advanced Research Journal in Science, Engineering and Technology}

Vol. 8, Issue 6, June 2021

DOI: $10.17148 /$ IARJSET.2021.8696

The crystallinity of prepared membranes was studied at room temperature using a Brucker's D- 8 advanced wide-angle $\mathrm{X}$-ray diffractometer. The X-ray source was Ni-filtered $\mathrm{CuK} \alpha$ radiation $(40 \mathrm{kV}, 30 \mathrm{~mA})$. The dried membrane of uniform thickness $(40 \pm 2 \mu \mathrm{m})$ was mounted on a sample holder and the diffraction was scanned in the reflection mode at an angle of $2 \theta$ over a range of $5-40^{\circ}$ at a constant speed of $8 \% \mathrm{~min}$.

2.3.3. Differential scanning calorimetry (DSC)

Thermal properties of pure PVA and its crosslinked membranes were studied using a differential scanning calorimeter (DSCQ 20, TA Instruments, Waters LLC, New Castle, Delawave, USA). Sample weights ranged from 9-10 mg and heated from ambient to $250{ }^{\circ} \mathrm{C}$ at a heating rate of $10{ }^{\circ} \mathrm{C} / \mathrm{min}$.

2.3.4. Thermogravimetric analysis (TGA)

Thermal stability of the membranes was investigated using a thermogravimetric analyzer (SDTQ 600, TA Instruments Waters LLC, New Castle, Delawave, USA). The sample weights ranged from 9-10 mg were heated from ambient to 600 ${ }^{\circ} \mathrm{C}$ at a heating rate of $10{ }^{\circ} \mathrm{C} / \mathrm{min}$.

2.3.5. Scanning electron microscopy (SEM)

The surface and cross-section views of pure PVA and its crosslinked membranes were examined using a scanning electron microscope (JEOL, JSM-400 А, Tokyo, Japan). Before photographing, all the samples were dried in vacuum and coated with a conductive layer (400 ̊) of sputtered gold.

2.3.6. Mechanical strength measurement

Mechanical properties such as tensile strength and percentage elongation at break were measured as per ASTM D638 method using 4302 model Houns Field Universal Testing Machine (UTM), UK.

2.4. Swelling measurement

\section{Total Sorption}

The percent degree of membrane swelling was determined by taking the known weights of the dried membrane samples and immersing in different compositions of water-IPA mixtures in sealed vessels at $40{ }^{\circ} \mathrm{C}$ for $24 \mathrm{~h}$. The swollen membranes were weighed as quickly as possible after superfluous liquid was wiped out with tissue paper on a digital microbalance (Mettler, B204-S, Toledo, Switzerland) with an accuracy of $\pm 0.01 \mathrm{mg}$. All the experiments were performed at least three times and the results were averaged. The increased weight is equal to the total weight of IPA and water sorbed by the membrane.

\section{Sorption selectivity}

The amount of water sorbed by the membranes was analyzed by Karl-Fischer titration. From the total sorption weight and corresponding water content of the membrane sorption selectivity of the membrane for water was calculated and expressed in terms of separation factor $\left(\alpha_{\text {sep }}\right)$ for sorption from the following equation:

$$
\alpha_{\text {sep }}=\frac{P_{w} / P_{I P A}}{F_{w} / F_{I P A}}
$$

where $\mathrm{P}$ and $\mathrm{F}$ are the mass fractions of permeate and feed, respectively; subscripts $\mathrm{w}$ and IPA, respectively denote water and isopropanol.

\subsection{Pervaporation experiment}

PV experiments were accomplished using the in-house designed set-up describe in detail in our previous work [27]. The effective surface area of the membrane in contact with the feed mixture was $34.23 \mathrm{~cm}^{2}$ and the capacity of the feed compartment was about $250 \mathrm{~cm}^{3}$. The vacuum in the downstream side of the PV cell was maintained [1.333224 x $10^{3}$ $\mathrm{Pa}$ (10 Torr)] using a two-stage vacuum pump (Toshniwal, Chennai, India). The test membrane was allowed to equilibrate for about two hours in the feed compartment at the measured temperature before performing the experiment. The experiments were carried out at 30,40 , and $50{ }^{\circ} \mathrm{C}$. IPA/water mixtures were used as feed solutions in the following mass ratios: 10/90, 20/80, 30/70, 40/60, 50/50 and 60/40, 70/30. The permeate was collected in a trap immersed in liquid nitrogen jar on the downstream side of the PV cell at fixed intervals of time. Permeate thus obtained was weighed on a digital microbalance to determine the flux. The compositions of water and IPA were estimated by measuring the refractive index of the mixture within an accuracy of \pm 0.0001 units using Abbe's refractometer (Atago-3T, Tokyo, Japan) and by comparing it with a standard graph that was established with the known compositions of water/IPA mixtures. All the experiments were performed at least three times and the results were averaged. The results of permeation for waterIPA mixtures during the pervaporation were reproducible within the admissible range.

The efficiency of the membranes employed in PV experiments was assessed in terms of total flux (J), separation factor $\left(\alpha_{\text {sep }}\right)$ and pervaporation separation index (PSI). These were respectively calculated using the following equations: $J=\frac{W}{A . t}$ 


\section{International Advanced Research Journal in Science, Engineering and Technology}

Vol. 8, Issue 6, June 2021

DOI: 10.17148/IARJSET.2021.8696

$\alpha_{\text {sep }}=\frac{P_{w} / P_{I P A}}{F_{w} / F_{I P A}}$

$P S I=J\left(\alpha_{\text {sep }}-1\right)$

where $\mathrm{W}$ represents the mass of permeate $(\mathrm{kg})$; $\mathrm{A}$ is the effective membrane area $\left(\mathrm{m}^{2}\right)$; $\mathrm{t}$ is the permeation time $(\mathrm{h})$; $\mathrm{P}$ and $\mathrm{F}$ are the mass fractions of permeate and feed, respectively; subscripts $\mathrm{w}$ and IPA, respectively denote water and isopropanol.

\section{RESULTS AND DISCUSSION}

\subsection{Membrane characterization}

\subsubsection{FTIR studies}

Fig. 2 illustrates the FTIR spectra of pristine PVA and its Glutaraldehyde crosslinked membranes. A characteristic strong and broad band exhibited at around 3400-3500 $\mathrm{cm}^{-1}$ [9] in pure PVA membrane, corresponds to O-H stretching vibrations of the hydroxyl groups. This is due to strong intermolecular and intramolecular hydrogen bonding. This band is decreased to $3435 \mathrm{~cm}^{-1}$ in crosslinked membrane, indicating that crosslinking reduced the extent of hydrogen bonding.

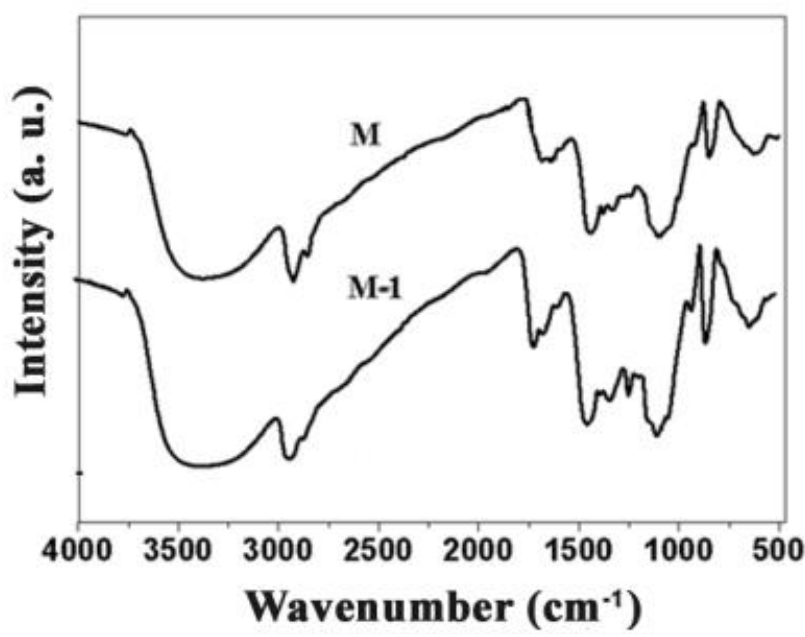

Fig. 2. FTIR spectra of pure PVA and modified PVA membranes: (M) 0; (M-1) 5 mass\% of GA+2.5wt\% of NaY zeolite. Multiple bands appeared at $1643 \mathrm{~cm}^{-1}, 1150 \mathrm{~cm}^{-1} 1000 \mathrm{~cm}^{-1}, 717 \mathrm{~cm}^{-1}, 580 \mathrm{~cm}^{-1}$, and $450 \mathrm{~cm}^{-1}$ are assigned to stretching vibrations of $-\mathrm{CH},-\mathrm{C}-\mathrm{O}-\mathrm{C}$, and $-\mathrm{C}=\mathrm{O}$ from glutaraldehyde, $\mathrm{PVA}$ and vibrations of $-\mathrm{O}-\mathrm{Al}-\mathrm{O},-\mathrm{Si}-\mathrm{O},-\mathrm{SiOH}$ groups, from $\mathrm{NaY}$ zeolite.

3.1.2. WXRD studies

In order to study the effect of crosslinking on the membrane morphology, wide-angle X-ray diffraction study was employed for the membranes and the patterns thus obtained are presented in Fig. 3. Generally, when the polymer contains crystalline domains, the diffraction peaks are sharp and their intensities are high whereas for amorphous polymer they are broad. The crystallinity of PVA arises from extensive hydrogen bonding by small hydroxyl groups occupying $\mathrm{d}$ and 1 sites in polymer chain within single crystal lattice. As this PVA crosslinked there is a change in the spacing and peak intensity also decreases thereby decreasing the crystallinity. The loss in crystallinity is also due to the incorporation of filler NaY zeolite.

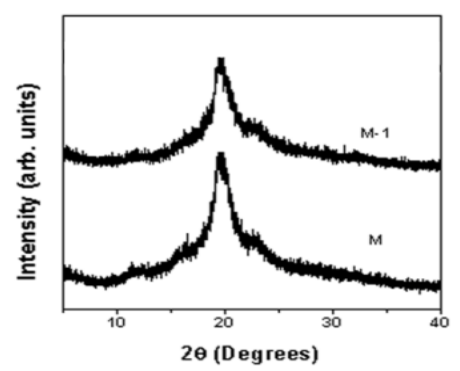




\section{International Advanced Research Journal in Science, Engineering and Technology}

Vol. 8, Issue 6, June 2021

DOI: $10.17148 /$ IARJSET.2021.8696

Fig. 3. Wide-angle X-ray diffraction patterns of pure PVA and modified PVA membranes: (M) 0; (M-1) 5 mass\% of $\mathrm{GA}+2.5 \mathrm{wt} \%$ of $\mathrm{NaY}$ zeolite.

From the Fig. 3, it is observed that the diffraction pattern of pure PVA membrane exhibits a typical peak at $2 \theta=20^{\circ}$ which can be assigned to the mixture of (101) and (200) crystalline planes [10,33]. As the membranes crosslinked, the intensity of this peak was decreased gradually as can be seen from the XRD patterns.

3.1.3. DSC studies

Differential scanning calorimetric measurements were carried out for pure PVA and its crosslinked membranes. The change in physical properties in the polymer membranes due to crosslinking is reflected in their glass transition temperature $\left(\mathrm{T}_{\mathrm{g}}\right)$ and melting point $\left(\mathrm{T}_{\mathrm{m}}\right)$ that have been confirmed by the DSC results. The DSC thermogram of pure PVA membrane shows a $\mathrm{T}_{\mathrm{g}}$ at $85^{\circ} \mathrm{C}$ and melting temperature around $228{ }^{\circ} \mathrm{C}$. It is clearly evident from the thermogram that $\mathrm{T}_{\mathrm{g}}$ of the membranes was increased by crosslinking as well as addition of zeolite. This is due to decreased freevolume in the PVA matrix which confirms the crosslinking reaction between hydroxyl group of PVA and glutaraldehyde in the membrane matrix and zeolite brings the physical changes in the morphology. The DSC curves also reveal about the melting temperature, which shifts from 228 to $205{ }^{\circ} \mathrm{C}$ by the incorporation of glutaraldehyde content. This is attributed due to reduced crystallinity of PVA by the chemical crosslinking reaction with glutaraldehyde, which breaks the molecular symmetry of PVA matrix to some extent.

3.1.4. SEM studies

Fig. 4 illustrates the scanning electron micrographs of both surface and cross-sectional views of pure PVA and its crosslinked membranes. From the micrographs, it is observed that surface view of pure membrane is smooth. However, only for the crosslinked zeolite filled membrane the uneven surface was noticed. This might be due to crosslinking segments and by the incorporation of zeolite content in pure PVA membrane.

(A)

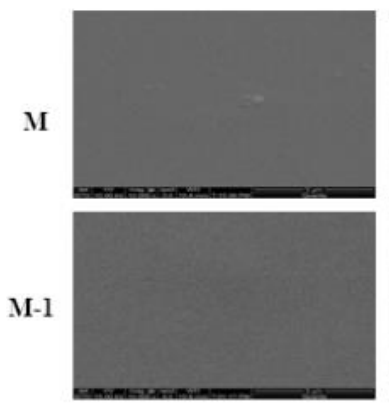

(B)

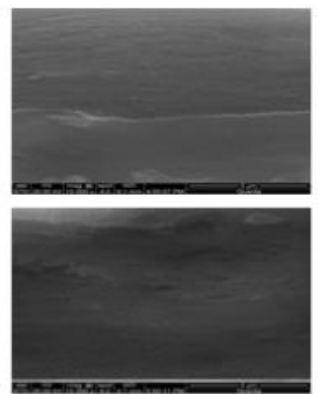

Fig. 4. SEM micrographs of pure PVA and modified PVA membranes: (M) 0; (M-1) 5 mass $\%$ of GA+2.5wt $\%$ of NaY zeolite: (A) surface view; (B) cross-sectional view.

\subsubsection{Mechanical properties}

The tensile strength and tensile elongation of a membrane often determines its suitability for PV applications. Therefore, to demonstrate the effect of crosslinking and zeolite content on the mechanical properties of pure PVA, we have measured the tensile strength and tensile elongation of the resulting crosslinked membranes including the membrane of pure PVA, and the data generated are present in Table 1.

Table 1

Tensile strength and \% elongation of PVA and modified PVA membranes.

\begin{tabular}{|c|c|c|}
\hline Membrane & $\begin{array}{c}\text { Tensile strength Mpa } \\
( \pm 5.0 \%)\end{array}$ & $\begin{array}{c}\text { Tensile elongation } \% \\
( \pm 6.0 \%)\end{array}$ \\
\hline $\mathrm{M}$ & 65 & 383 \\
\hline $\mathrm{M}-1$ & 90 & 242 \\
\hline
\end{tabular}

From the data, it is observed that the tensile strength of the membranes was increased remarkably with increasing the cross-linking because of existence of bonding with hydroxyl groups of PVA by the elimination of water molecules occurs. This results in the reduction of free-volume and hindrance of chain mobility in the membrane matrix attribute to increased tensile strength. On the contrary, the tensile elongation at break was decreased. This is quite obvious, when there is a restriction of chain mobility and reduction of free-volume in the membrane matrix. This clearly suggests that the physical and chemical cross-linking enhances the mechanical properties of the membranes.

3.2. Effects of feed composition and crosslinking on membrane swelling

The mechanism of sorption depends on the microstructure of the membrane, affinity of penetrating molecules and mutual interaction between the penetrants. Therefore, the degree of sorption is playing an important role in PV 


\section{International Advanced Research Journal in Science, Engineering and Technology}

Vol. 8, Issue 6, June 2021

\section{DOI: $10.17148 /$ IARJSET.2021.8696}

process that controls the transport of permeating molecules under the influence of chemical potential gradient [29]. In order to study the effects of feed composition on membrane swelling, the percent degree of swelling of all the membranes was plotted as a function of mass $\%$ of water in the feed at $30{ }^{\circ} \mathrm{C}$ as shown in Fig. 5. It is observed that the degree of swelling was increased for all the membranes with increasing the mass $\%$ of water in the feed. This is due to an interaction between water molecules and the membrane, owing to the presence of interactive hydrophilic groups (-OH) in the membrane matrix. This is expected due to polarity of water than that of IPA, which preferentially interacts with membrane resulting to an increased degree of swelling.

Fig. 5. Variation of degree of swelling with different mass $\%$ of water in the feed for crosslinked membranes. 3.3. Effect of feed composition and crosslinking on pervaporation

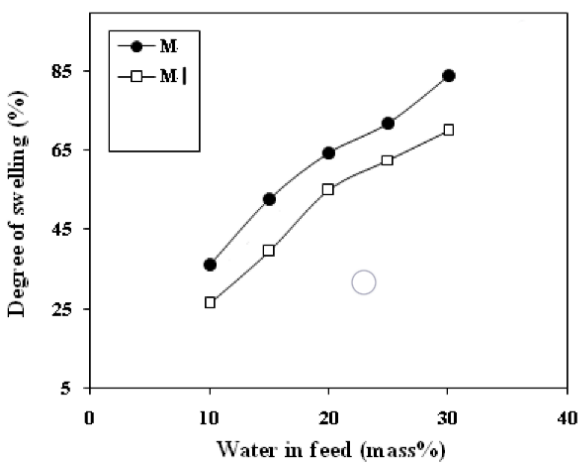

The effects of feed composition as well as cross-linking density on total permeation flux at $30{ }^{\circ} \mathrm{C}$ is shown in Fig. 6 . It is observed that all the membranes exhibited enhance in permeation flux with increasing water composition in the feed, and this behavior is in good agreement with results observed in swelling study. This is due to increased selective interactions between water molecules and the membrane. On the other hand, the permeation flux was decreased the crosslinking density. This is due to a significant reduction of free-volume followed by a decrease in chain mobility [30].

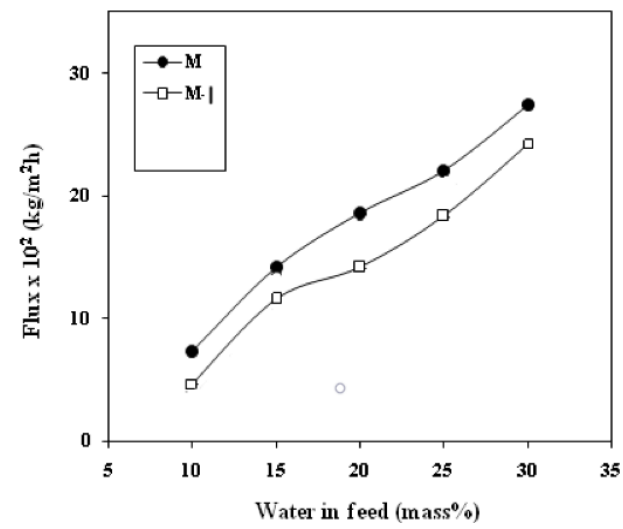

Fig. 6. Variation of total pervaporation flux with different mass $\%$ of water in the feed for crosslinked membranes.

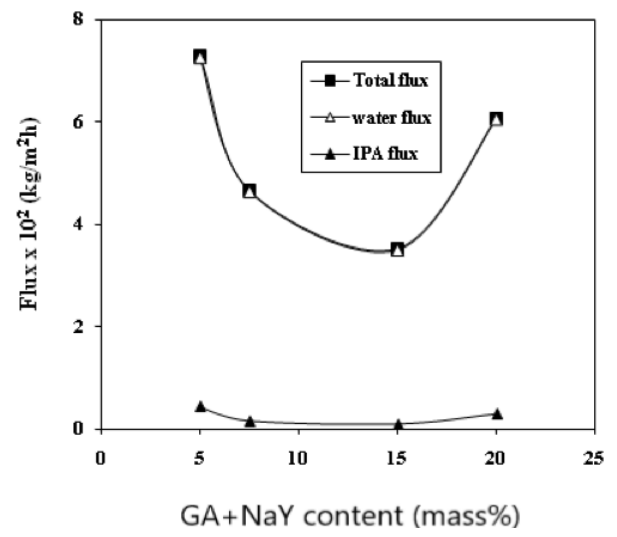




\section{International Advanced Research Journal in Science, Engineering and Technology}

Vol. 8, Issue 6, June 2021

DOI: $10.17148 /$ IARJSET.2021.8696

Fig. 7. Variation of total flux, and fluxes of water and isopropanol with 10 mass $\%$ of water in the feed for crosslinked membranes.

To assess the extent of permeation of individual components, we have plotted the total flux, and fluxes of water and IPA as a function of crosslinking content in the membrane for 10 mass $\%$ of water in the feed as shown in the Fig.7. From the plot, it is clear that the total flux and flux of water are overlapping, but the flux of IPA is negligibly small, indicating that the membranes developed in the present study exhibited the highest selectivity towards water with a tremendous improvement in the flux.

In PV process, the overall selectivity of a membrane is generally explained on the basis of interaction of membrane with the permeating molecules, their size and pore diameter of the membrane [31]. Fig.8 displays the effect of water compositions on the selectivity for the membrane. It is observed that the selectivity of the membrane was decreased with increasing the mass $\%$ of water in the feed. This is because of increased membrane swelling and plasticized upstream membrane layer, which allow some of IPA molecules too towards the permeate side along with water molecules and this

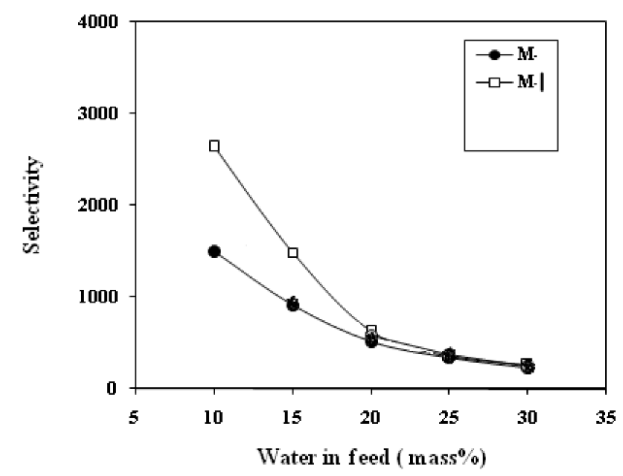

Fig. 8. Variation of selectivity with different mass $\%$ of water in the feed for crosslinked membranes.

leads to a negative impact on the selectivity of membrane. From Fig. 8, it is also observed that selectivity was increased significantly in membrane M to M-1 upon increasing the chemical and physical cross-linking which intern changes the morphology of membrane. As a result, the mobility of polymeric chains was apparently dropped and the absolute freevolume to diffuse the permeants through the membrane was decreased. Thus, water molecules having relatively small molecular size can diffuse through the crosslinked membranes easily rather than isopropanol molecules having large molecular size.

3.4. Effect of crosslinking on PSI

The PSI is the product of total permeation flux and separation factor, which determines the membrane performances in PV applications. This parameter can also be used as a relative guideline for the design of a membrane for large scale process and also for the selection of a membrane with an optimal combination of flux and selectivity. Fig. 9 shows the variation of PSI as a function of mass $\%$ of GA+NaY at $30{ }^{\circ} \mathrm{C}$ for 10 mass $\%$ of water in the feed. It is observed that there was a significant change in the PSI values with increasing the GA+NaY content, suggesting that the membranes incorporated with 15 mass $\%$ of $\mathrm{GA}+\mathrm{NaY}$, exhibited an excellent performance for the separation of water-isopropanol mixtures.

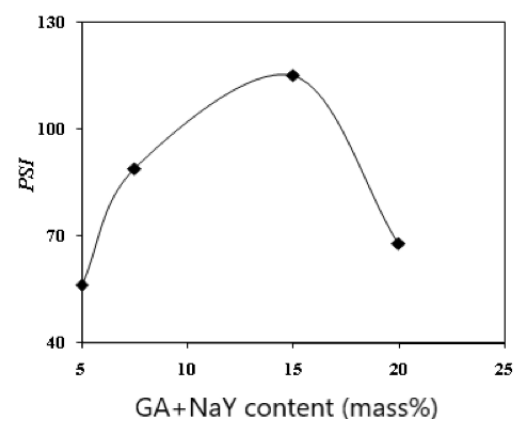

Fig. 9. Variation of pervaporation separation index with 10 mass $\%$ of water in the feed for crosslinked membranes 3.6. Diffusion coefficient

Transport of binary liquid mixtures through a polymeric membrane in PV process is generally described by solutiondiffusion mechanism, which occurs in three steps: sorption, diffusion and evaporation. Thus, permeation rate and selectivity are governed by the solubility and diffusivity of each component of the feed to be separated. In PV process, 


\section{International Advanced Research Journal in Science, Engineering and Technology}

Vol. 8, Issue 6, June 2021

\section{DOI: $10.17148 /$ IARJSET.2021.8696}

because of the establishment of fast equilibrium distribution between the bulk feed and the upstream surface of a membrane, diffusion step controls the transport of penetrants [32]. Therefore, it is of course important to estimate the diffusion coefficient of the penetrating molecules to understand the mechanism of molecular transport. From Fick's law of diffusion, the diffusion flux can be expressed as [33]:

$J_{i}=-D_{i} \frac{d C_{i}}{d x}$

where $J$ is the permeation flux per unit area $\left(\mathrm{kg} / \mathrm{m}^{2} \mathrm{~s}\right)$, D is the diffusion coefficient $\left(\mathrm{m}^{2} / \mathrm{s}\right), \mathrm{C}$ is the concentration of permeant $\left(\mathrm{kg} / \mathrm{m}^{3}\right)$, subscript $i$ stands for water or IPA, and $\mathrm{x}$ is the diffusion length $(\mathrm{m})$. For simplicity, it is assumed that the concentration profile along the diffusion length is linear. Thus, $\mathrm{D}_{\mathrm{i}}$ can be calculated with the following equation [34]:

$D_{i}=\frac{J_{i} \delta}{C_{i}}$

where $\delta$ is the membrane thickness. The calculated values of $\mathrm{D}_{\mathrm{i}}$ at $40{ }^{\circ} \mathrm{C}$ are presented in Table 2 .

Table 2

Diffusion coefficients of water and isopropanol at different mass $\%$ of water in the feed

\begin{tabular}{|c|c|c|c|c|}
\hline \multirow{2}{*}{$\begin{array}{c}\text { Mass } \% \\
\text { of water }\end{array}$} & \multicolumn{2}{|c|}{$\mathrm{D}_{\mathrm{w}} \times 10^{8}\left(\mathrm{~cm}^{2} / \mathrm{s}\right)$} & \multicolumn{2}{|c|}{$\mathrm{D}_{\mathrm{IPA}} \times 10^{9}\left(\mathrm{~cm}^{2} / \mathrm{s}\right)$} \\
\cline { 2 - 5 } & $\mathrm{M}$ & $\mathrm{M}-1$ & $\mathrm{M}$ & $\mathrm{M}-1$ \\
\hline 10 & 14.9 & 9.43 & 0.32 & 0.11 \\
\hline 15 & 17.4 & 17.2 & 0.69 & 0.37 \\
\hline 20 & 19.0 & 14.4 & 1.21 & 0.75 \\
\hline 25 & 19.1 & 14.9 & 1.67 & 1.34 \\
\hline 30 & 21.1 & 16.5 & 2.95 & 2.29 \\
\hline
\end{tabular}

Similar to PV study, the diffusion coefficients of water as well as IPA were decreased significantly from membrane M to $\mathrm{M}-1$, due to a reduction of free-volume in the membrane matrix. However, there is a considerable increase in diffusion coefficients in both the cases with increasing the amount of water in the feed. Such an increase is quite obvious at higher composition of water in the feed due to a significant enhancement of interaction between membrane and the permeants. In spite of this, the magnitude of the diffusion coefficients of water is quite high in comparison with that of IPA, suggesting that the membranes developed in this study with GA are still selective toward water molecules even at higher concentration of water in the feed.

3.7. Effect of temperature on membrane performance

In order to study the effect of operating temperature on the performance of the membranes, pervaporation experiments were carried out at different temperatures for water-IPA mixtures at 10 mass $\%$ of water in the feed and resulting values are presented in Table 3.

Table 3

Pervaporation flux and separation selectivity at different temperatures at 10 mass $\%$ of water in the feed

\begin{tabular}{|c|c|c|c|c|}
\hline \multirow{2}{*}{$\begin{array}{c}\text { Mass } \% \\
\text { of water }\end{array}$} & $\mathrm{J} \times 10^{2}\left(\mathrm{~kg} / \mathrm{m}^{2} \mathrm{~h}\right)$ & \multicolumn{2}{|c|}{$\alpha_{\text {sep }}$} \\
\cline { 2 - 5 } & $\mathrm{M}$ & $\mathrm{M}-1$ & $\mathrm{M}$ & $\mathrm{M}-1$ \\
\hline 30 & 7.29 & 4.65 & 1491 & 2638 \\
\hline 40 & 7.45 & 5.39 & 1276 & 1397 \\
\hline 50 & 9.13 & 8.77 & 1207 & 1276 \\
\hline
\end{tabular}

It is observed that the permeation rate was increased from 30 to $50{ }^{\circ} \mathrm{C}$ for all the membranes while decreasing the separation selectivity. Generally, this happens because of two major reasons. Firstly, as the temperature increases the viscosity of the permeating molecules decreases due to decrease of cohesive forces between the permeants. Secondly, an increase of thermal energy intensifies the motions of polymer chain segments, creating more free-volume in the 


\section{International Advanced Research Journal in Science, Engineering and Technology}

Vol. 8, Issue 6, June 2021

DOI: $10.17148 /$ IARJSET.2021.8696

polymer matrix. However, in the present study, the second reason is ruled out since the experiments were performed well below the glass transition temperature of PVA. Therefore, the viscosity of permeating molecules played a vital role in controlling the transport of selective permeants through the membrane. This in turn results in an increase of total permeation flux, while suppressing the selectivity. Thus, the temperature dependence of permeation and diffusion has prompted us to estimate the activation energies for permeation and diffusion using the Arrhenius type equation [35]:

$$
X=X_{o} \exp \left(\frac{-E_{x}}{R T}\right)
$$

where $X$ represents permeation (J) or diffusion (D). $X_{0}$ is a constant representing pre-exponential factor of $J_{0}$ or $D_{0}$. $E_{x}$ represents activation energy for permeation or diffusion depending upon the transport process under consideration and RT is the usual energy term. As the feed temperature increases, the vapor pressure in the feed compartment also increases, but the vapor pressure at the permeate side is not affected. This results in an increase of driving force with increasing the temperature.

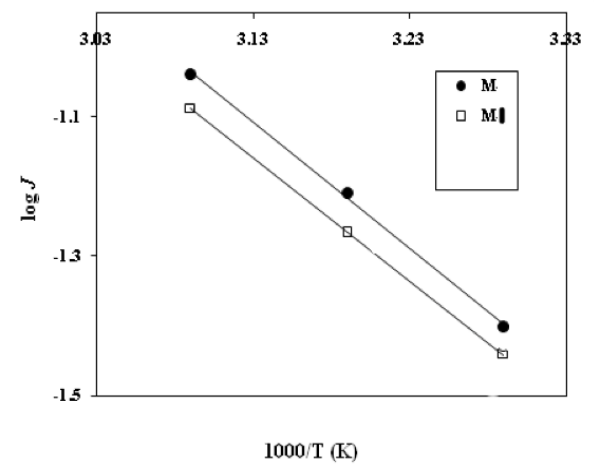

Fig. 10. Variation of $\log \mathrm{J}$ with temperature for crosslinked membranes at 10 mass $\%$ of water in the feed.

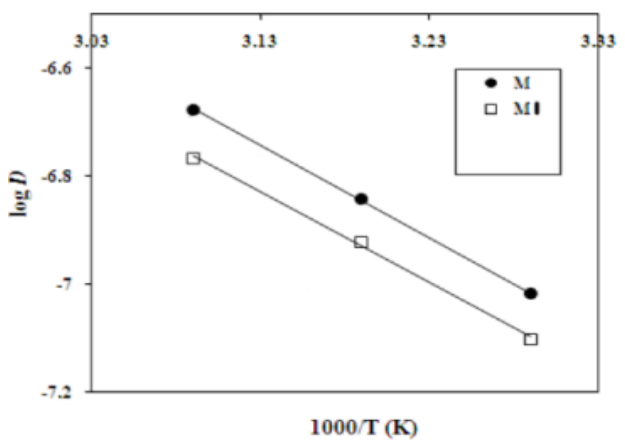

Fig. 11. Variation of $\log D$ with temperature for crosslinked membranes at 10 mass $\%$ of water in the feed.

Arrhenius plots of $\log \mathrm{J}$ and $\log \mathrm{D}$ versus temperature are shown in Figs. 10 and 11, respectively. In both the cases, linear behavior was observed, suggesting that permeability and diffusivity follow an Arrhenius trend. From the least squares fits of these linear plots, the activation energies for total permeation $\left(E_{p}\right)$ and diffusion $\left(E_{D}\right)$ were estimated. Similarly, we have also estimated the activation energies for permeation of water $\left(E_{\mathrm{pw}}\right)$, and diffusion of water ( $\left.\mathrm{E}_{\mathrm{Dw}}\right)$ and IPA $\left(\mathrm{E}_{\mathrm{DIPA}}\right)$, but the plots are not given to avoid the crowd. The values thus obtained are presented in Table 4.

Table 4

Arrhenius activation parameters for permeation, diffusion, and heat of sorption.

\begin{tabular}{|c|c|c|}
\hline $\begin{array}{c}\text { Parameters } \\
(\mathrm{kJ} / \mathrm{mol})\end{array}$ & $\mathrm{M}$ & $\mathrm{M}-1$ \\
\hline $\mathrm{E}_{\mathrm{p}}$ & 8.97 & 18.87 \\
\hline $\mathrm{E}_{\mathrm{D}}$ & 9.04 & 19.23 \\
\hline $\mathrm{E}_{\mathrm{pw}}$ & 8.91 & 18.80 \\
\hline $\mathrm{E}_{\mathrm{Dw}}$ & 9.17 & 19.09 \\
\hline $\mathrm{E}_{\mathrm{DIPA}}$ & 17.55 & 40.30 \\
\hline
\end{tabular}




\section{International Advanced Research Journal in Science, Engineering and Technology}

Vol. 8, Issue 6, June 2021

DOI: $10.17148 /$ IARJSET.2021.8696

\begin{tabular}{|l|l|l|}
\hline$\Delta \mathrm{H}_{\mathrm{s}}$ & -0.07 & -0.36 \\
\hline
\end{tabular}

From Table 4, it is observed that both $E_{p}$ and $E_{D}$ values were increased with increasing the GA content, indicating that both permeation and diffusion processes require more energy for transport of molecules through the membrane in view of the rigidity and compactness of molecular structure in the membrane matrix. A significant difference was noticed between the apparent activation energy values for water $\left(\mathrm{E}_{\mathrm{Dw}}\right)$ and isopropanol $\left(\mathrm{E}_{\mathrm{DIPA}}\right)$, and the difference was increased correspondingly with increasing the GA content. This further suggests that membranes incorporated with higher amount of GA demonstrated greater separation efficiency towards water. The $E_{p}$ and $E_{D}$ values were ranged from 8.97 - 25.65 and $9.04-26.15 \mathrm{~kJ} / \mathrm{mol}$, respectively. Using these values, we have further calculated the heat of sorption as [35]: $\Delta H_{s}=E_{p}-E_{D}$

The resulting $\Delta \mathrm{H}_{\mathrm{s}}$ values are included in Table 5. The $\Delta \mathrm{H}_{\mathrm{s}}$ values obtained in the present study are negative for all the membranes, suggesting that sorption occurs by hole-filling mechanism and therefore, Langmuir's mode of sorption is predominant.

\section{CONCLUSIONS}

In this study, modified PVA membranes were prepared using GA as a crosslinker and NaY zeolite as a filler using solution-casting technique. Both $\mathrm{GA}+\mathrm{NaY}$ enhances the hydrophilicity of the membrane. An increase of GA+NaY content in the membrane results to an increase of selectivity. This was explained on the basis of increased hydrophilicity (solvation property) and establishments of crosslinks by the incorporation of GA in the membrane. Both total flux and flux of water are almost overlapping with each other especially for membranes having GA, suggesting that the membranes developed in the present study are highly selective towards water. The membrane containing 15 mass $\%$ of GA+NaY exhibited the highest separation selectivity of 3,452 with a flux of $3.51 \times 10^{-2} \mathrm{~kg} / \mathrm{m}^{2} \mathrm{~h}$ at $30{ }^{\circ} \mathrm{C}$ for 10 mass $\%$ of water in the feed. The PV separation index data also support that the membrane with higher amount of GA (upto 15 mass\%) demonstrated an excellent PV performance. When we increase the temperature, the permeation rate was found to increase, while suppressing the selectivity. This was attributed to decreased interaction between permeates, permeate and membrane at higher temperature. The $E_{p}$ and $E_{D}$ values were ranged from 8.97- 25.65 and $9.04-26.15 \mathrm{~kJ} / \mathrm{mol}$, respectively. All the membranes exhibited negative $\Delta \mathrm{H}_{\mathrm{s}}$ values, indicating that sorption is mainly dominated by the Langmuir's mode of sorption, giving an exothermic contribution.

\section{ACKNOWLEDGEMENTS}

Authors sincerely thank the Department of Physics, Indian Institute of Science, Bangalore, for extending facility in characterization of developed membranes.

\section{REFERENCES}

1. R. C. Munoz, Breakthroughs on tailoring pervaporation membranes for water desalination: A review, Water Research, 187 (2020) 116428. 2. S.K. Choudhari, A.A. Kittur, S.S. Kulkarni, M.Y. Kariduraganavar, Development of novel blocked diisocyanate crosslinked chitosan membranes for pervaporation separation of water-isopropanol mixtures, J. Membr. Sci. 302 (2007) 197-206.

3. P. Luis, Chap.3-Pervaporation. In Fundamental Modelling of Membrane Systems, 1st ed.; Elsevier: Amsterdam, The Netherlands, 2018; pp. 71-102.

4. $\quad$ Baker, R. Membrane Technology and Applications, 2nd ed.; John Wiley \& Sons, Ltd.: Chichester, UK, 2004.

5. P. Cíhal,; Vopi`cka, O.; Lan`c, M.; Kludský, M.; Velas, J.; Hrdlǐcka, Z.; Michalcová, A.; Dendisová, M.; Friess, K. Poly(butylene succinate)-cellulose triacetate blends: Permeation, pervaporation, sorption and physical structure. Polym. Test. 2018, 65, 468-479.

6. Dutta, B.K.; Sikdar, S.K. Separation of azeotropic organic liquid mixtures by pervaporation. Aiche J. 1991, 37, 581-588.

7. M.Y. Kariduraganavar, J.G. Varghese, S.K. Choudhari, R.H. Olley, Organic-inorganic hybrid membranes: solving the trade-off phenomenon between permeation flux and selectivity in pervaporation, Ind. Eng. Chem. Res. 48 (2009) $4002-4013$.

8. B.P. Tripathi, M. Kumar, A. Saxena, V.K. Shahi, Bifunctionalized organic-inorganic charged nanocomposite membrane for pervaporation dehydration of ethanol, J. Colloid Int. Sci. 346 (2010) 54-60.

9. S. Kahya, E.K. Solak, O. Sanli, Sodium alginate/poly(vinyl alcohol) alloy membranes for the pervaporation, vapor permeation and vapor permeation with temperature difference separation of dimethylformamide/water mixtures: A comparative study, Vacuum 84 (2010) $1092-1102$.

10. S.S. Kulkarni, A.A. Kittur, M.I. Aralaguppi M.Y. Kariduraganavar, Synthesis and characterization of hybrid membranes using poly(vinyl alcohol) and tetraethylorthosilicate for the pervaporation separation of water-isopropanol mixtures, J. Appl. Polym. Sci. 94 (2004) $1304-1315$.

11. A.A. Kittur, S.M. Tambe, S.S. Kulkarni, M.Y. Kariduraganavar, Pervaporation separation of water-acetic acid mixtures through NaY zeolite incorporated sodium alginate membranes, J. Appl. Polym. Sci. 94 (2004) 2101-2109.

12. N. Alghezawi, O. Şanli, L. Aras, G. Asman, Separation of acetic acid-water mixtures through acrylonitrile grafted poly(vinyl alcohol) membranes by pervaporation, Chem. Eng. Process. 44 (2005) 51-58.

13. R. Jiraratananon, A. Chanachai, R.Y.M. Huang. D. Uttapap, Pervaporation dehydration of ethanol-water mixtures with chitosan/hydroxyethylcellulose (CS/HEC) composite membranes I. Effect of operating conditions, J. Membr. Sci. 195 (2002) 143-151.

14. Bharathi M; Senthil Kumaran S; Edwin Samson P. "Influence of nano silica particles on quasistatic mechanical and low velocity impact properties of Carbon-glass-Sunn hemp/epoxy in intra-inter ply hybrid composites". International Research Journal on Advanced Science Hub,2021doi: 10.47392/irjash.2021.3753.1017

15. Naveenkumar M; Karthick B; Naveen Kumar C; Rajavel R. "INVESTIGATION OF COIR FIBER REINFORCED EPOXY COMPOSITES". International Research Journal on Advanced Science Hub, 1, 1, 2019, 23-27. doi: 10.47392/irjash.2019.04 


\section{International Advanced Research Journal in Science, Engineering and Technology}

Vol. 8, Issue 6, June 2021

\section{DOI: $10.17148 /$ IARJSET.2021.8696}

16. S. Chaudhari, Y.S. Kwon, M.Y. Shon, S. E. Nam, Y.I. Park, Stability and pervaporation characteristics of PVA and its blend with PVAm membranes in a ternary feed mixture containing highly reactive epichlorohydrin, RSC Adv., 2019, 9, 5908-5917.

17. Elavarasan A. "Fourier Transform Infrared, X-Ray Diffraction and Energy Dispersive X-Ray Analysis Studies on the Adsorption of Copper Ii Ions Prepared From Mimusops Elengi Leaves in Aqueous Solution against Acid Activated Carbon". International Research Journal on Advanced Science Hub, 2, 8, 2020, 52-56. doi: 10.47392/irjash.2020.93

18. S. G. Chaudhri, B. H. Rajai and P. S. Singh, Nanoscale homogeneity of silica-poly(vinyl alcohol) membranes by controlled crosslinking via sol-gel reaction in acidified and hydrated ethanol, RSC Adv., 2015, 5, 65862-65869.

19. T. Jose, S. C. George, S. Thomas, Tunable physicochemical properties of PVA nanocomposite membranes for enhanced pervaporation performance, Polym. Eng. Sci., 2018, 58, 849-858.

20. V. Gimenez, A. Mantecon, J.C. Ronda, V. Cadiz, Poly(vinyl alcohol) modified with carboxylic acid anhydrides: crosslinking through carboxylic groups, J. Appl. Polym. Sci. 65 (1997) 1643-1651.

21. M. Sajjan, B. K. Jevankumar, A. A. Kittur, M. Y. Kariduraganavar, Development of novel grafted hybrid PVA membranes using glycidyltrimethyl ammonium chloride for pervaporation separation of water-isopropanol mixtures, J. Ind. Eng. Chem., 2013, $19,427-437$.

22. Y.M. Lee, B.K. Oh, Pervaporation of water-acetic acid mixture through poly(4-vinylpyridine-co-acrylonitile) membrane, J. Membr. Sci. 85 (1993) 13-20.

23. Ramezani, H.; Azizi, S.N.; Hosseini, S.R. NaY zeolite as a platform for preparation of Ag nanoparticles arrays in order to construction of H2O2 sensor. Sens. Actuators B 2017, 248, 571-579.

24. Broach, R.W. Zeolite Types and Structures. In Zeolites in Industrial Separation and Catalysis, 1st ed.; Kulprathipanja, S., Ed.; John Wiley \& Sons: Glasgow, UK, 2010; pp. 27-60.

25. Singleton, N.L.; Huddersman, K.D.; Needham, M.I. The adsorption properties of NaY zeolite for separation of aromatic triazoles. J. Chem. Soc. Faraday Trans. 1998, 94, 3777-3780.

26. Sawamura, K.-i.; Furuhata, T.; Sekine, Y.; Kikuchi, E.; Subramanian, B.; Matsukata, M. Zeolite Membrane for Dehydration of Isopropylalcohol—Water Mixture by Vapor Permeation. ACS Appl. Mater. Interfaces 2015, 7, 13728-13730.

27. Kita, H.; Fuchida, K.; Horita, T.; Asamura, H.; Okamoto, K. Preparation of Faujasite membranes and their permeation properties. Sep. Purif. Technol. 2001, 25, 261-268.

28. Xu Yongquan1, 2, Cai Lianguo1, Shao Lei1 and Chen Jianfeng, Preparation and characterization of NaY zeolite in a rotating packed bed, Pet. Sci., 9 (2012) 106-109.

29. Katsuki, H., Furuta, S. \& Komarneni, S. Microwave Versus Conventional-Hydrothermal Synthesis of NaY Zeolite. Journal of Porous Materials 8, 5-12 (2001). https://doi.org/10.1023/A:1026583832734.

30. M.Y. Kariduraganavar, A.A. Kittur, S.S. Kulkarni, K. Ramesh, Development of novel pervaporation membranes for the separation of waterisopropanol mixtures using sodium alginate and NaY zeolite, J. Membr. Sci. 238 (2004) 165-175.

31. D.S. Kim, H.B. Park, J.W. Rhim, Y.M. Lee, Proton conductivity and methanol transport behavior of cross-linked PVA/PAA/silica hybrid membranes, Solid State Ionics 176 (2005) 117-126.

32. S.K. Choudhari, M.Y. Kariduraganavar, Development of novel composite membranes using quaternized chitosan and Na ${ }^{+}-M_{M T}$ clay for the pervaporation dehydration of isopropanol, J. Colloid Interface Sci. 338 (2009) 111-120.

33. C.K. Yeom, K.H. Lee, A study on permeation of a liquid mixture through PVA membranes having a crosslinking gradient structure in pervaporation, J. Appl. Polym. Sci. 59 (1996) 1271-1279.

34. P.S. Rachipudi, A.A. Kittur, S.K. Choudhari, J.G. Varghese, M.Y. Kariduraganavar, Development of polyelectrolyte complexes of chitosan and phosphotungstic acid as pervaporation membranes for dehydration of isopropanol, European Polym. J. 45 (2009) $3116-3126$.

35. A.A. Kittur, M.Y. Kariduraganavar, U.S. Toti, K. Ramesh, T.M. Aminabhavi, Pervaporation separation of water-isopropanol mixtures using ZSM-5 zeolite incorporated poly(vinyl alcohol) membranes, J. Appl. Polym. Sci. 90 (2003) 2441-2448.

36. Yamasaki, T. Iwatsubo, T. Masuoka, K. Mizoguchi, Pervaporation of ethanol/water through a poly(vinyl alcohol)/cyclodextrin (PVA/CD) membrane, J. Membr. Sci. 89 (1994) 111-117.

37. S.S. Kulkarni, S.M. Tambe, A.A. Kittur, M.Y. Kariduraganavar, Preparation of novel composite membranes for the pervaporation separation of water-acetic acid mixtures, J. Membr. Sci. 285 (2006) 420-431.

38. J.G. Varghese, A.A. Kittur, P.S. Rachipudi, M.Y. Kariduraganavar, Synthesis, characterization and pervaporation performance of chitosang-polyaniline membranes for the dehydration of isopropanol, J. Membr. Sci. 364 (2010) 111-121. 